\title{
A Bayesian network based study on determining the relationship between job stress and safety climate factors in occurrence of accidents
}

\author{
Amir Hossein Khoshakhlagh ${ }^{1}$, Saeid Yazdanirad ${ }^{2,3^{*}}$ (1), Masoud Motalebi Kashani ${ }^{4}$, Elham Khatooni ${ }^{5}$, \\ Yaser Hatamnegad ${ }^{6}$ and Sohag $\mathrm{Kabir}^{7}$
}

\begin{abstract}
Background: Job stress and safety climate have been recognized as two crucial factors that can increase the risk of occupational accidents. This study was performed to determine the relationship between job stress and safety climate factors in the occurrence of accidents using the Bayesian network model.

Methods: This cross-sectional study was performed on 1530 male workers of Asaluyeh petrochemical company in Iran. The participants were asked to complete the questionnaires, including demographical information and accident history questionnaire, NIOSH generic job stress questionnaire, and Nordic safety climate questionnaire. Also, work experience and the accident history data were inquired from the petrochemical health unit. Finally, the relationships between the variables were investigated using the Bayesian network model.

Results: A high job stress condition could decrease the high safety climate from 53 to $37 \%$ and increase the accident occurrence from 72 to $94 \%$. Moreover, a low safety climate condition could increase the accident occurrence from 72 to $93 \%$. Also, the concurrent high job stress and low safety climate could raise the accident occurrence from 72 to 93\%. Among the associations between the job stress factor and safety climate dimensions, the job stress and worker's safety priority and risk non-acceptance (0.19) had the highest mean influence value.

Conclusion: The adverse effect of high job stress conditions on accident occurrence is twofold. It can directly increase the accident occurrence probability and in another way, it can indirectly increase the accident occurrence probability by causing the safety climate to go to a lower level.
\end{abstract}

Keywords: Job stress, Safety climate, Accident, Bayesian network

\section{Background}

The International Labor organization describes workplace accidents as unplanned and unpredictable events that create obvious injuries [1]. Based on the statistics,

*Correspondence: saeedyazdanirad@gmail.com

${ }^{3}$ Social Determinants of Health Research Center, Shahrekord University

of Medical Sciences, Shahrekord, Iran

Full list of author information is available at the end of the article over 264 million occupational accidents and 350,000 mortalities due to those occur every year in the world [2]. The financial burden of occupational accidents and diseases in compared to that of costly Diseases such as cancers, Alzheimer, human immunodeficiency virus (HIV), and cardiovascular illnesses is higher [3]. Different studies have been investigated the causes of accidents. Some of these agents included individual, organizational, environmental, social, job factors [4]. Of effective factors, 
job stress and safety climate play important roles in the occurrence of accidents.

Job stress, as one of the most common occupational problems, seriously threatens staff health in the world. The results of studies show that higher levels of job stress can directly affect the body's immune system and mental health. This stress also causes disorders and illnesses such as depression and anxiety, immune deficiency disorders, headaches, musculoskeletal pain, and cardiovascular disease $[5,6]$. Furthermore, it can affect individual and organizational performances [7]. Based on the results of studies, occupational stress affects productivity, absenteeism, burnout, and job turnover $[8,9]$. There are various definitions of job stress in the literature. McGrath and Altman state that stress is the fundamental imbalance between an individual's capability and job demand that leads to severe consequences [10]. There are different occupational factors affecting job stress, such as job control, conflict at work, job satisfaction, mental demand, physical environment, social support, and workload and responsibility [11]. If there are no coordination among job requirements, abilities, and desires, then stress can lead to many behavioral, physical, and psychological consequences. The International Labor Organization estimates the costs of job stress to be 1 to $3.5 \%$ of the Gross Domestic Product (GDP) of each country [12]. The study results in the developed countries indicate that nearly $30 \%$ of the staff suffer from job stress [13]. In addition to the mental and functional consequences, job stress can lead to unsafe behaviors and accidents through impaired focus and decision-making. The results of several studies have proven that stress plays a vital role in $37 \%$ of industrial accidents \& injuries [13].

Safety climate is another critical factor affecting staff health and accident occurrence. Safety climate defines the workers' perceptions of the organizational prioritization related to workplace safety compared to business demands [14-16]. Accordingly, safety climate has various attributes such as management's commitment to safety and safety communication, encouraging the workers to the safety behavior in order to promote safety and performance outcomes $[16,17]$. The results of several meta-analysis studies show that the safety climate affects safety outcomes such as accidents and injuries, as well as safety compliance and participation behaviors $[18,19]$. The results of a review study performed by Kalteh et al. also showed that increasing the level of safety climate can reduce accident incidence rate and improve safety performance [20]. The planned behavior theory describes the role of the safety climate in causing safety behavior [21]. Based on this theory, three central components, including attitude toward the behavior, subjective norms, and perceived behavioral control, are effective in creating unsafe behavior. Fogarty and Shaw demonstrated that the management attitude and safety climate significantly affect these three components and regulate the behavior [21]. Moreover, the safety climate can make the accident occurrence through other paths such as job stress, which can affect job satisfaction, staff engagement, and turnover [22]. Dollard et al. stated that a psychosocial safety climate adjusts the job demand - resource interaction and controls job stress [23]. However, there may also be a reverse path from work stress toward a safe climate. In other words, job stress factors may affect the safety climate and lead to accidents through this path. This assumption can be examined using the Bayesian network model. This type of model has been exploited to analyze the health and safety issues in previous studies. Mohammadfam et al. applied the Bayesian network model for modeling and evaluating the safety behavior of the workers in the industry [24]. Mirzaei et al. represented a novel procedure for risk modeling of a hydrogen gasholder using the Fuzzy Bayesian Network [25]. Herrero et al. used the Bayesian network models for analyzing the effect of working conditions and psychological/physical symptoms on occupational accidents [26]. Ahn et al. exploited the Bayesian network model for diagnosing the relations between work-related musculoskeletal disorders and working characteristics [27]. In the present study, it was aimed to determine the relationship between job stress and safety climate dimensions in the occurrence of accidents using the Bayesian network model.

\section{Material and methods}

Figure 1 shows the workflow of the method used in this paper. The total steps of this study included preparing questionnaires, collecting data, and data analysis. The authors confirm that all methods were carried out in accordance with relevant guidelines and regulations of Helsinki.

\section{Participants}

This cross-sectional study was performed on 1530 male workers of Asaluyeh petrochemical company in Iran, from August 2018 to May 2019. The study population consists of the staff employed in various departments, including technical, electrical, machinery, maintenance, mechanical, welding, turning, and supervision units of the petrochemical company. Firstly, a list of people working in each department was created, and subjects were randomly selected from the list. All participants declared their informed consent, using the consent form provided by the medical ethics committee of Tehran University of medical sciences. Before the beginning of the study, the test stages were clearly explained to the participants. Inclusion criteria were having work experience for more 


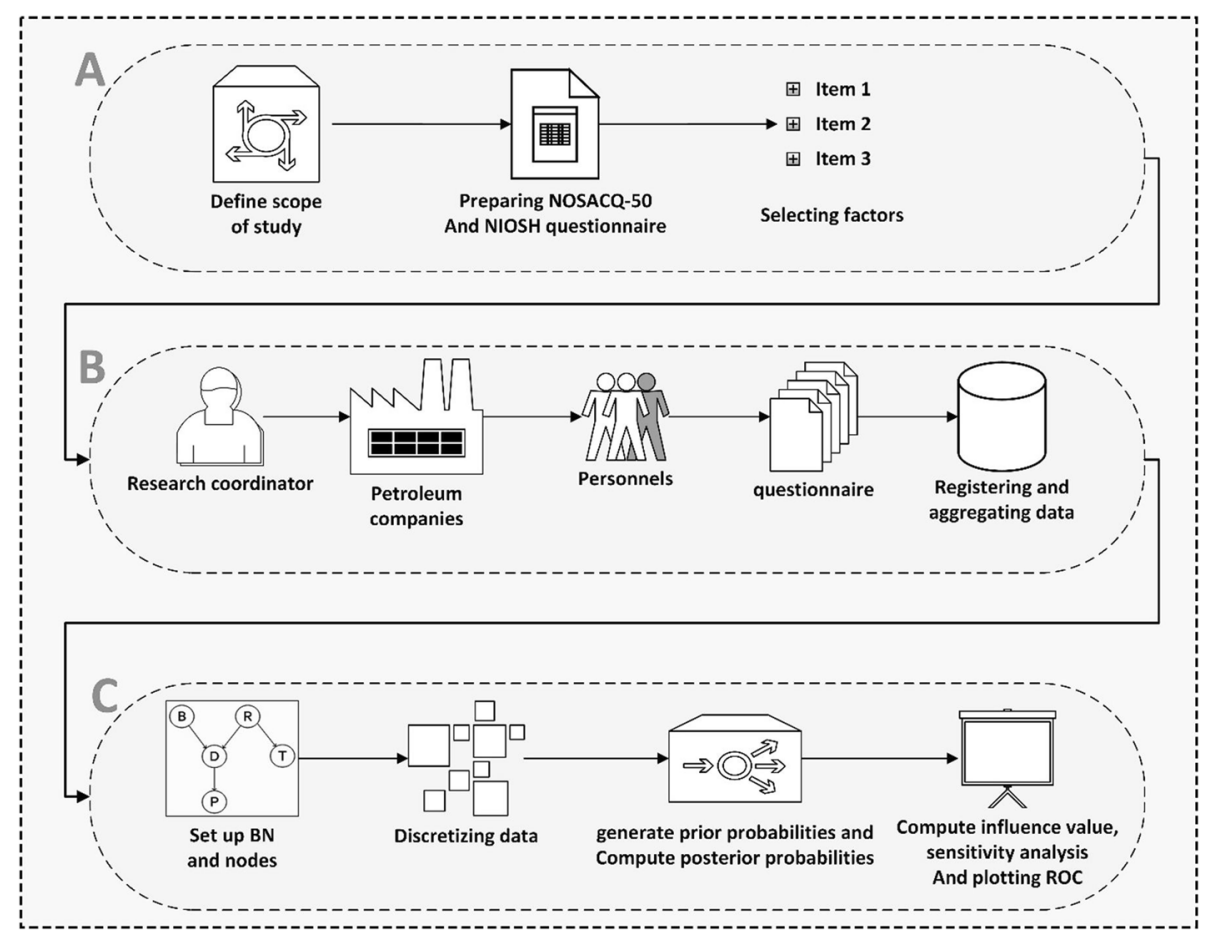

Fig. 1 The workflow of the method used in this paper

than one year and being literate. Exclusion criteria were lack of cooperation and lack of focus on completing the questionnaires.

\section{Data acquisition}

Before the beginning of the study, the goals and stages of the study were clearly explained to the participants. Then, they were given the necessary training on how to complete the questionnaires. The questionnaires were completed in the presence of the researchers at the rest times. The questionnaires included demographical information, accident history questionnaire, NIOSH Generic Job Stress Questionnaire (GJSQ), and Nordic Safety Climate Questionnaire (NOSACQ-50). Also, work experience and the accident history data were inquired from the petrochemical health unit.

\section{Data collection instruments}

\section{Demographic data and accident history questionnaire}

The demographic data including age, education, marital status, job type, working department, working experience, body mass index, and smoking were collected using a researcher-made questionnaire. Also, participants were questioned about their accident experience and accident type at workplaces during the past year.

\section{NIOSH generic job stress questionnaire (GJSQ)}

NIOSH Generic Job Stress Questionnaire (GJSQ) developed by the US National Institute for Occupational Safety and Health (NIOSH) was used to measure the different job stress factors among workers. Kazronian et al. [11] have evaluated and validated this questionnaire in Iranian firefighters. They claimed that the Cronbach Alpha Coefficient of this questionnaire is more than 0.7, and its Intra-Cluster Correlation Coefficient is 0.7. However, in the present study, the Cronbach Alpha Coefficient of the questionnaire and the Intra-Class Correlation Coefficient were calculated again. NIOSH Generic Job Stress Questionnaire (GJSQ) encompasses 21 parts or factors; including background information (7 questions), conflict at work (16 questions), employment opportunities (4 questions), general health (17 questions), health conditions (24 questions), feelings about his-self (10 questions), general job information (12 questions), job requirements (10 questions), job satisfaction (4 questions), mental demands (5 questions), non-work activities (7 questions), other health information (33 questions), physical environment (10 questions), problems at work (6 questions), social support (12 questions), work hazards (5 questions), work limitations (5 questions), workload and responsibility (11 questions), job (14 questions), and job future (5 questions). The answer options are different, including yes or no, false and true, Likert from one 
Table 1 The descriptive information of the participants' demographic variable

\begin{tabular}{|c|c|c|c|}
\hline \multicolumn{2}{|l|}{ Demographic variable } & \multirow{2}{*}{$\begin{array}{l}\text { Frequency } \\
226\end{array}$} & \multirow{2}{*}{$\begin{array}{l}\text { Valid Percent } \\
14.8\end{array}$} \\
\hline Age (years) & $20-29$ & & \\
\hline & $30-39$ & 775 & 50.7 \\
\hline & $40-49$ & 471 & 30.8 \\
\hline & $50-59$ & 58 & 3.8 \\
\hline \multirow[t]{5}{*}{ Education degree } & Under diploma & 247 & 16.1 \\
\hline & diploma & 687 & 44.9 \\
\hline & Associate degree & 460 & 30.1 \\
\hline & Bachelor Degree & 127 & 8.3 \\
\hline & Master's degree & 9 & 0.6 \\
\hline \multirow[t]{4}{*}{ Job experience (years) } & $1-5$ & 124 & 8.1 \\
\hline & $5-10$ & 724 & 47.3 \\
\hline & $10-15$ & 427 & 27.9 \\
\hline & 15 and higher & 255 & 16.7 \\
\hline \multirow[t]{3}{*}{ Body mass index } & $17.5-20$ & 105 & 6.9 \\
\hline & $20-25$ & 585 & 38.3 \\
\hline & 25 and higher & 837 & 54.8 \\
\hline \multirow[t]{9}{*}{ Type of job } & Technical worker & 150 & 9.8 \\
\hline & Electrical worker & 131 & 8.6 \\
\hline & Machinery worker & 273 & 17.8 \\
\hline & Repairing worker & 281 & 18.4 \\
\hline & Conversion worker & 261 & 17.1 \\
\hline & Turnery worker & 187 & 12.2 \\
\hline & Welding worker & 128 & 8.4 \\
\hline & Mechanic worker & 64 & 4.2 \\
\hline & supervisor & 55 & 3.6 \\
\hline \multirow[t]{2}{*}{ Marital status } & single & 238 & 15.6 \\
\hline & married & 1292 & 84.4 \\
\hline \multirow[t]{2}{*}{ Smoking } & yes & 891 & 58.2 \\
\hline & no & 639 & 41.38 \\
\hline
\end{tabular}

Table 2 CPT for "accident state"

\begin{tabular}{llll}
\hline Safety climate & Job stress & yes & no \\
\hline low & low & 0.91 & 0.09 \\
low & high & 0.93 & 0.07 \\
high & low & 0.32 & 0.68 \\
high & high & 0.95 & 0.05 \\
\hline
\end{tabular}

to five, Likert from one to three, and open-ended answers [28]. The total score was calculated with the mean value of the scores in job stress scales.

\section{Nordic safety climate questionnaire (NOSACQ-50)}

It is a validated questionnaire on safety climate survey. A team of occupational safety experts from several Nordic countries including Denmark, Norway,
Iceland, Finland, and Sweden led by Pete Kines from the National Research Centre for the Working Environment (NRCWE) developed the questionnaire in 2011 [29]. This questionnaire has 50 questions and 7 subscales; including management's safety priority and ability (9 questions), management's safety empowerment (7 questions), management's safety justice (6 questions), worker's safety commitment (6 questions), worker's safety priority and non-acceptance risk (7 questions), peer safety communication, learning, and trust (8 questions), and worker's trust in the efficacy of safety systems (7 questions) [29]. Yousefi et al. [30] in 2016, have evaluated the validity and reliability of this questionnaire in Iran. Alpha Cronbach Coefficient of this questionnaire obtained was 0.94 . However, in the present study, Cronbach Alpha Coefficient and the IntraClass Correlation Coefficient were calculated again. In this questionnaire, the questions are answered via Likert ranging from one to four; including strongly disagree, disagree, agree, and strongly agree. The total score was calculated with the mean value of the scores in job stress scales.

\section{Data analysis \\ Statistical tests}

First, we discretized the any of understudy variables (the safety climate dimensions and occupational stress scales) with the Uniform-Width method into a dichotomous variable (low and high). Then, the statistical tests were carried out using SPSS software version 24. Descriptive statistics were calculated. Then the expectation-maximization method was applied to calculate and replace the missing values. Cronbach Alpha Coefficient and Internal Correlation Coefficient calculated by a two-way mixed analysis of variance. The result of this analysis was used for evaluating the validity and reliability of the questionnaires. Besides, the bivariate and multivariate correlations coefficients for the job stress and safety climate variables were calculated.

\section{Bayesian network modeling}

Bayesian Networks (BNs) are probabilistic and graphical models introduced by Pearl. In the present study, GeNIe academic software version 2.3 (university of Pittsburg) with an expert-knowledge base method was used. Five experts were asked to give their opinion on three possible relationships $(A \uparrow B, A \rightarrow B$, and $A \leftarrow B$ ) and for this purpose, the Dempster-Shafer theory was applied [31]. After creating the $\mathrm{BN}$ graphical structure, a Conditional Probability Table (CPT) was obtained from the developed model with the Expectation-Maximization algorithm [32]. In the next step, delta p sensitivity analysis was used to rank the factors corresponding to accident state [24], 


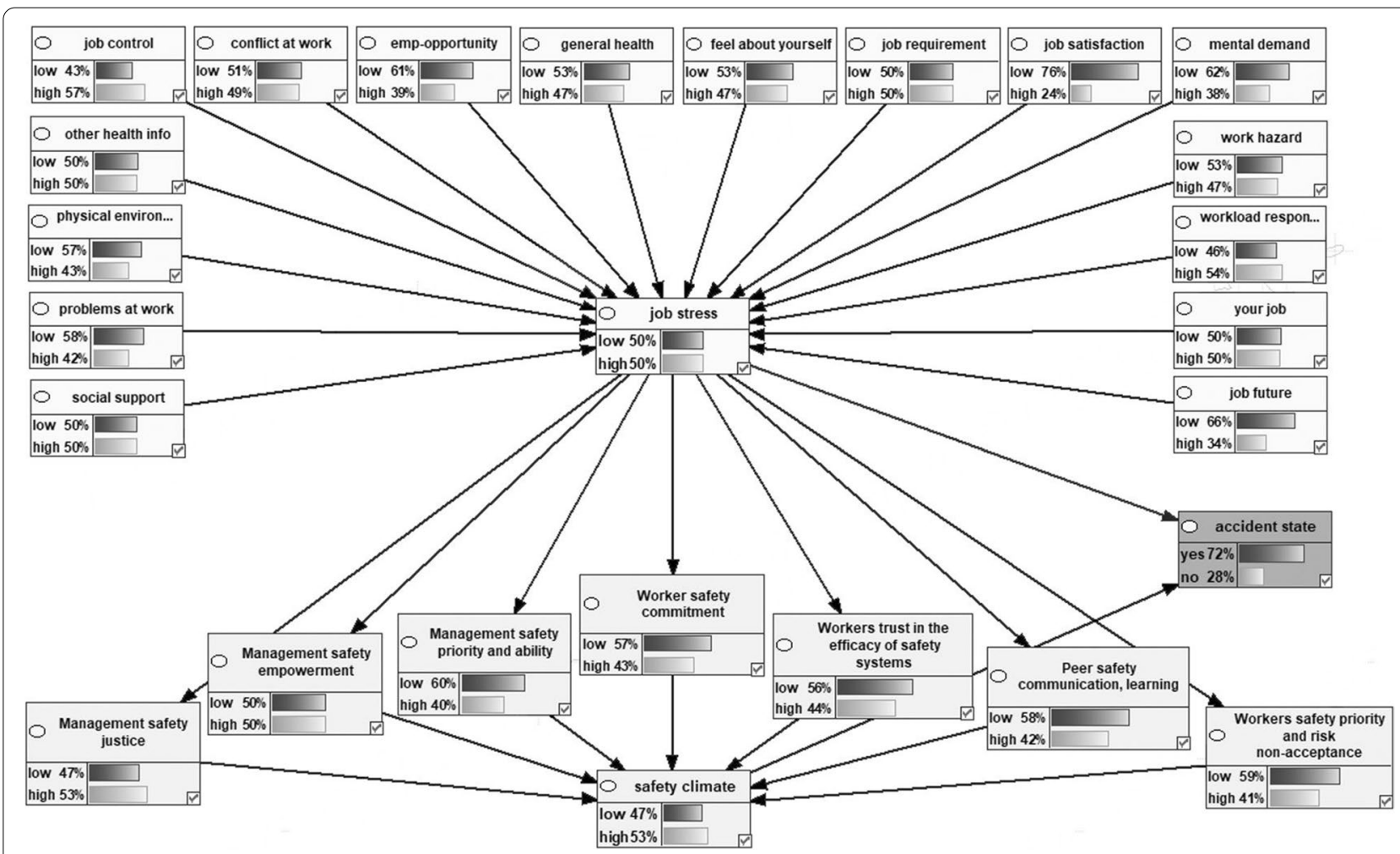

Fig. 2 Bayesian network model representing the dependencies among the variables the marginal probabilities of the studied variables

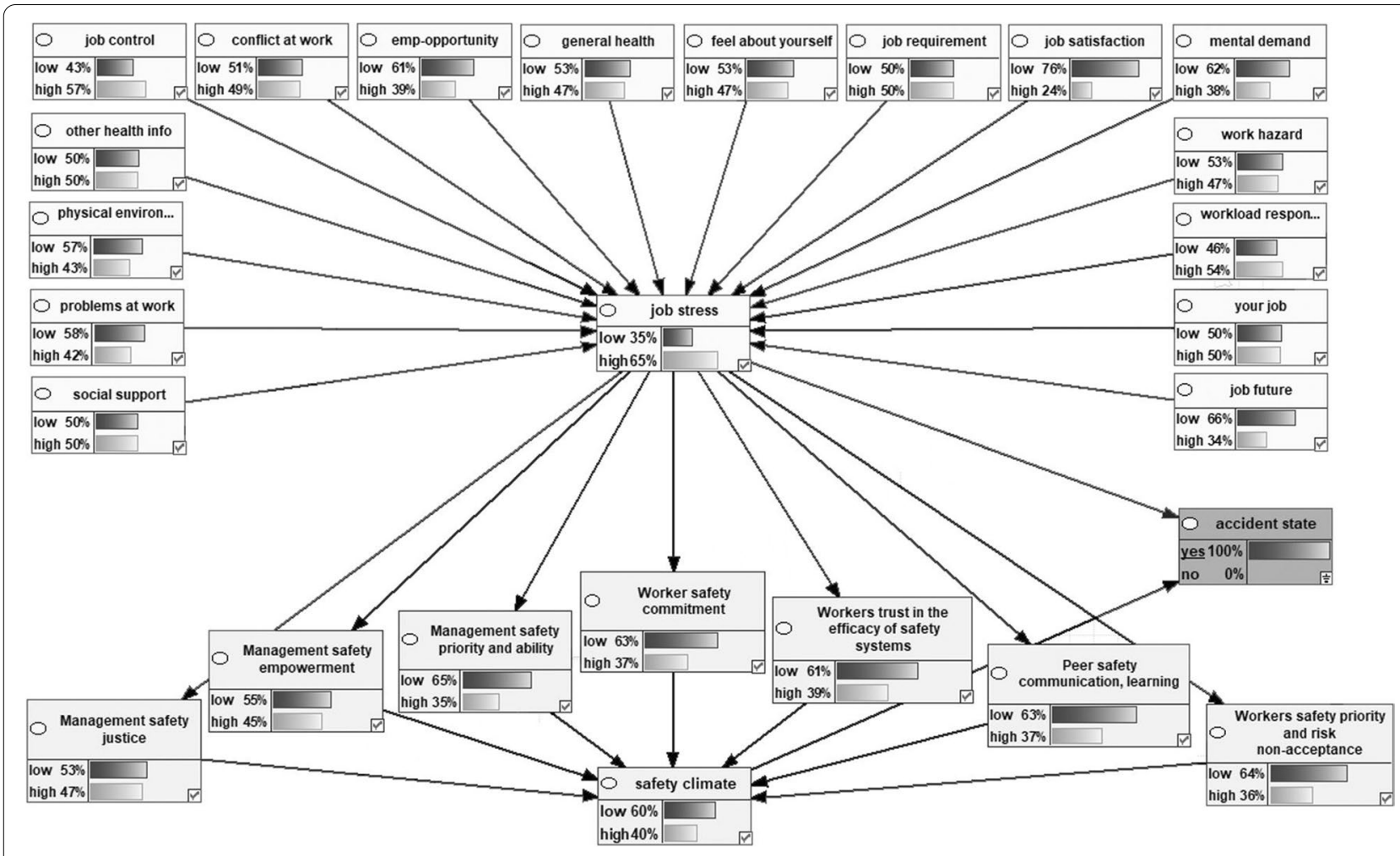

Fig. 3 Sensitivity analysis of accident occurrence 


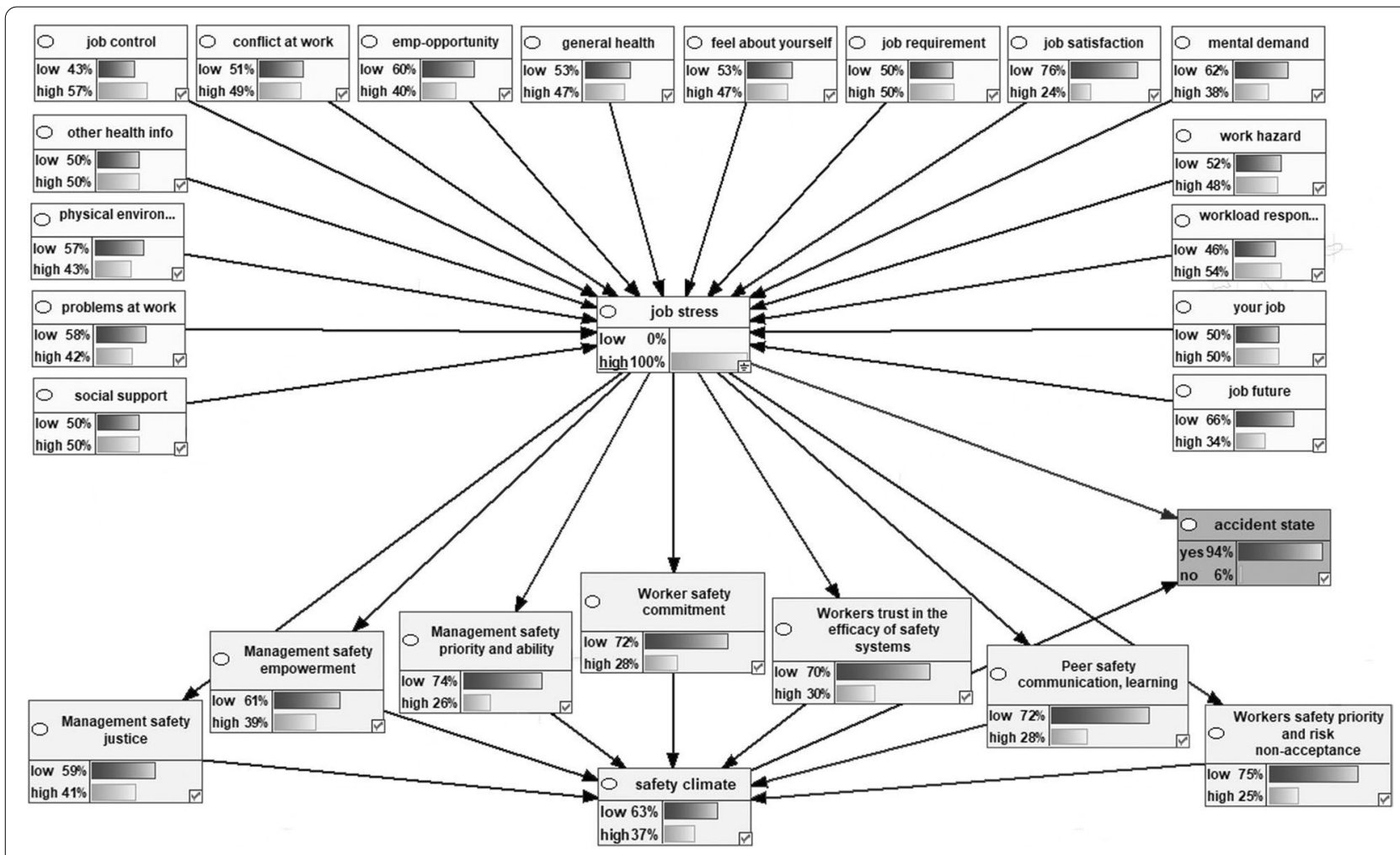

Fig. 4 Sensitivity analysis of job stress

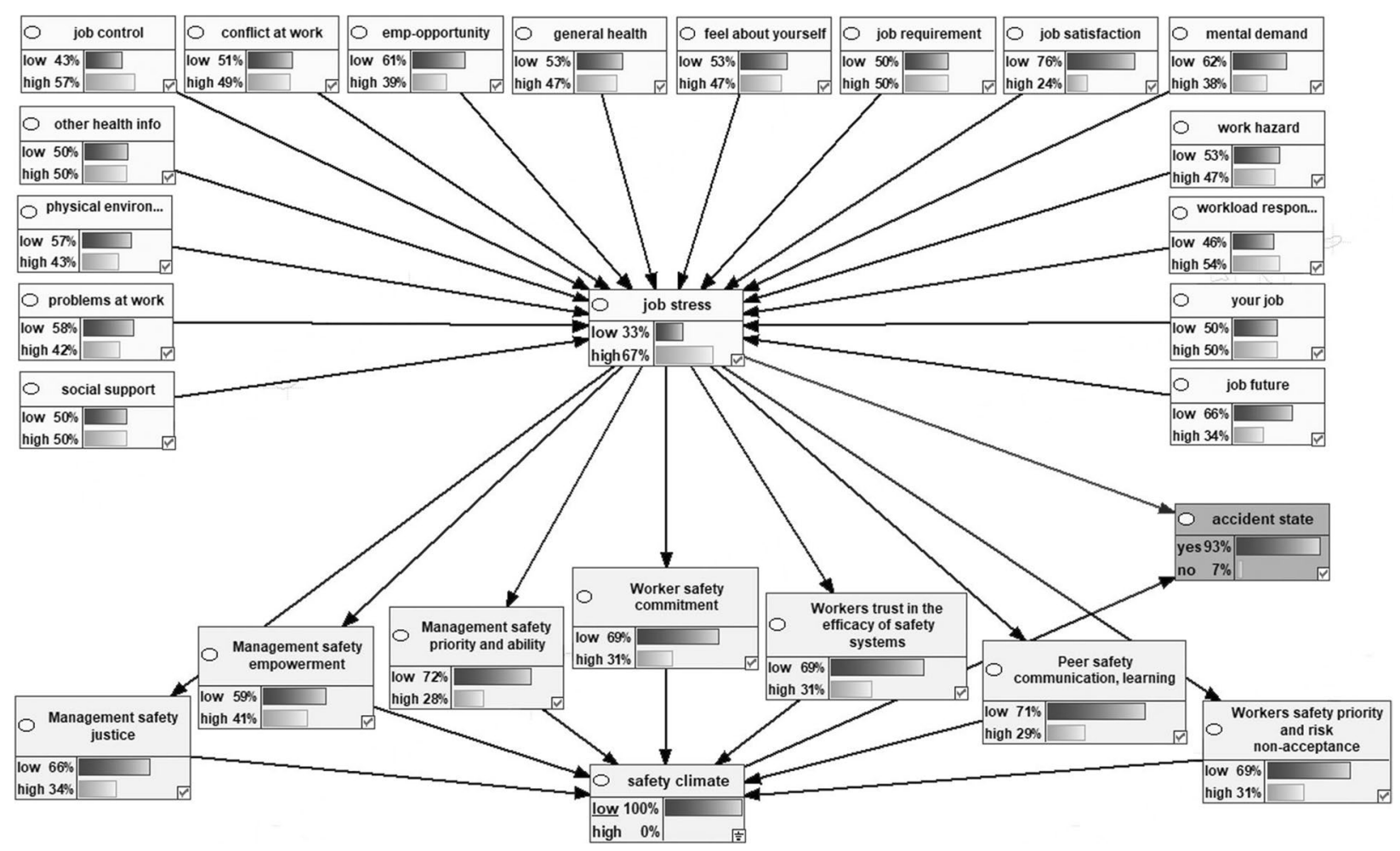

Fig. 5 Sensitivity analysis on safety climate 


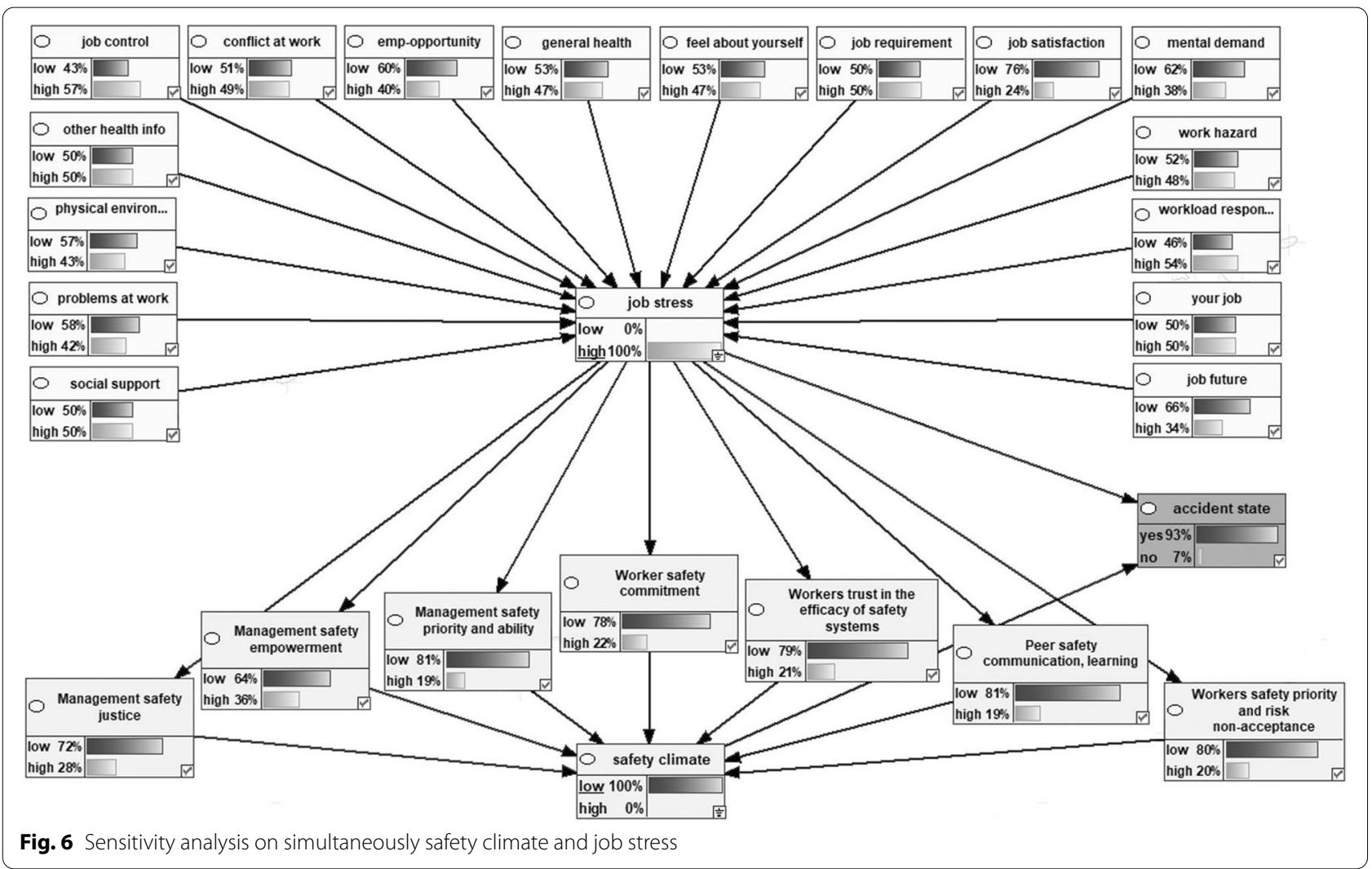

and finally,10-fold cross-validation analysis was also used to evaluate the model. Dataset was randomly divided into ten equal folds, and in any 10-repeat cross-validation, nine folds (9 subsamples) were used to train the Bayesian network model, and the remaining fold (1 subsample) was used to validate the model. A sensitivity analysis also was performed to investigate the effects of the statistically significant variables [33].

\section{Results}

According to the analysis of the collected data, the internal consistency of all dimensions is at an excellent level (Cronbach's alpha> 0.9). Also, based on the results of the two-way mixed model, the intra-class correlation coefficients for the reliability of a single rating, and the aggregated mean have excellent values. Table 1 shows the descriptive information of the participants' demographic variables. Most of the subjects were 30 to 39 years old (50.7\%), at high school education level $(44.9 \%), 5$ to 10 years of job experience (47.3\%), with body mass index higher than 25 (54.8\%), repairing and machinery job type (36.2\%), married (84.4\%), and smoker (58.2\%). Table 2 also represents the Conditional Probability Table (CPT) for accident state, which reports the relationship coefficient among the variables.
Figure 2 shows the Bayesian network model representing the dependencies among the variables the marginal probabilities of the studied variables. Figures 3, 4, 5, 6 also indicate the sensitivity analyses. At the occurrence of the accident with the probability of $100 \%$, the probability of the high job stress enhanced from 50 to $65 \%$, and the probability of the high safety climate decreased from 53 to $40 \%$. For safety climate dimensions, most decreases were related to the management's safety justice from 53 to $47 \%$ and the worker's safety commitment from 43 to $37 \%$. For the high job stress condition with the probability of $100 \%$, the probability of the high safety climate decreased from 53 to $37 \%$ and the probability of the accident occurrence increased from 72 to $94 \%$. For safety climate dimensions, most decreases were related to the worker's safety priority, and risk non-acceptance from 41 to $25 \%$ and the worker's safety commitment from 43 to $28 \%$. For the low safety climate condition with the probability of $100 \%$, the probability of the accident occurrence increased from 72 to $93 \%$. For the safety climate dimensions, most decreases were related to the management's safety justice from 53 to $34 \%$. Besides, at the concurrently low safety climate and high job stress with the probability of $100 \%$, the probability of accident occurrence increased from 72 to $93 \%$. Lastly, for the safety climate dimensions, 
Table 3 Predicted probability of "occupational accident = no" (\%) corresponded to other factors states

\begin{tabular}{|c|c|c|c|c|}
\hline Safety Climate and Job Stress Dimensions & Low \% & High \% & Variation $^{\dagger}$ & Rank \\
\hline Job stress & 78.01 & -77.72 & 155.73 & 1 \\
\hline Safety climate & -73.05 & 66.37 & 139.42 & 2 \\
\hline Peer safety communication, learning, and trust & -26.04 & 35.37 & 61.41 & 3 \\
\hline Management's safety justice & -32.19 & 28.27 & 60.45 & 4 \\
\hline Management's safety priority and ability & -23.11 & 34.13 & 57.25 & 5 \\
\hline Worker's safety commitment & -24.13 & 32.60 & 56.73 & 6 \\
\hline Worker's trust in the efficacy of safety systems & -24.30 & 30.68 & 54.98 & 7 \\
\hline Worker's safety priority and non-acceptance risk & -22.06 & 32.14 & 54.20 & 8 \\
\hline Management's safety empowerment & -23.49 & 23.51 & 47.00 & 9 \\
\hline General health & 0.33 & -0.37 & 0.70 & 10 \\
\hline Work hazard & 0.30 & -0.33 & 0.63 & 11 \\
\hline Other health info & 0.30 & -0.30 & 0.60 & 12 \\
\hline Employment opportunity & 0.22 & -0.34 & 0.56 & 13 \\
\hline Your job & 0.24 & -0.25 & 0.49 & 14 \\
\hline Mental demand & 0.18 & -0.30 & 0.48 & 15 \\
\hline Workload responsibility & 0.24 & -0.21 & 0.44 & 16 \\
\hline Job requirement & 0.22 & -0.22 & 0.43 & 17 \\
\hline Problems at work & 0.14 & -0.19 & 0.33 & 18 \\
\hline Job control & 0.16 & -0.12 & 0.27 & 19 \\
\hline Feel about yourself & 0.10 & -0.12 & 0.22 & 20 \\
\hline Job satisfaction & -0.04 & 0.13 & 0.17 & 21 \\
\hline Social support & 0.08 & -0.08 & 0.16 & 22 \\
\hline Conflict at work & 0.08 & -0.08 & 0.16 & 23 \\
\hline Job future & -0.04 & 0.08 & 0.13 & 24 \\
\hline Physical environment & -0.01 & 0.01 & 0.02 & 25 \\
\hline
\end{tabular}

${ }^{\dagger}$ Variation $=\mid$ Low $\%|+|$ High $\% \mid$

most decreases were also related to the management's safety justice from 53 to $28 \%$.

Table 3 demonstrated ranked posterior probabilities of occurring accidents. As Table 4 shows, the calculated values are from the associations between factors. The most effective mean values were related to the job stress and accident occurrence association (0.39), the safety climate and accident occurrence relation (0.34), and the management's safety justice and safety climate $(0.19)$. For the association between the job stress factor and safety climate dimensions, the job stress and worker's safety priority and risk non-acceptance relation (0.19) had the highest mean value. For the job stress factor and job stress scales associations, the associations of the job stress factor with general health (0.004), employment opportunity (0.004), and other health information (0.003) showed the highest mean values.

A ROC curve was drawn to investigate the validity of the fitted Bayesian model, and the area under the curve was calculated (Fig. 7). This value was 0.8353 . The parameters of the confusion matrix related to the classification of the occupational accident status also were computed (Table 5). The values of the sensitivity, specificity, and accuracy of the model were equal to 87,82 , and $85 \%$, respectively.

\section{Discussion}

In the present study, a Bayesian model was fitted to analyze the inter-association between job stress, safety climate, and accident occurrence. This model has been used to clarify how job stress can affect accident occurrence, directly and indirectly, through the safety climate. The results showed that the presented model has good validity. The validity and reliability of the used questionnaires were investigated and were accepted as valid and reliable tools. In general, the results obtained from the model showed that a high job stress condition could decrease the high safety climate from 53 to $37 \%$ and increase the accident occurrence from 72 to $94 \%$. Analysis of the other paths in the model also demonstrated that a low safety climate condition could increase the accident occurrence from 72 to $93 \%$. Also, the concurrent high job stress and 
Table 4 The calculated influence values from the association of the factors in developed model

\begin{tabular}{|c|c|c|}
\hline Parent & Child & Influence value \\
\hline Job stress & Accident state & 0.39 \\
\hline Safety climate & Accident state & 0.34 \\
\hline Management's safety justice & Safety climate & 0.19 \\
\hline Job stress & Worker's safety priority and risk non-acceptance & 0.19 \\
\hline Job stress & Management's safety priority and ability & 0.18 \\
\hline Job stress & Peer safety communication, learning, and trust & 0.17 \\
\hline Job stress & Worker's safety commitment & 0.17 \\
\hline Job stress & Worker's trust in the efficacy of safety systems & 0.16 \\
\hline Peer safety communication, learning, and trust & Safety climate & 0.15 \\
\hline Management's safety priority and ability & Safety climate & 0.14 \\
\hline Worker's trust in the efficacy of safety systems & Safety climate & 0.14 \\
\hline Job stress & Management's safety justice & 0.13 \\
\hline Worker's safety commitment & Safety climate & 0.13 \\
\hline Job stress & Management's safety empowerment & 0.11 \\
\hline Worker's safety priority and risk non-acceptance & Safety climate & 0.11 \\
\hline Management's safety empowerment & Safety climate & 0.09 \\
\hline General health & Job stress & 0.004 \\
\hline Employment opportunity & Job stress & 0.004 \\
\hline Work hazard & Job stress & 0.003 \\
\hline Other health information & Job stress & 0.003 \\
\hline Mental demand & Job stress & 0.003 \\
\hline Your job & Job stress & 0.002 \\
\hline Workload responsibility & Job stress & 0.002 \\
\hline Job requirement & Job stress & 0.002 \\
\hline Problems at work & Job stress & 0.002 \\
\hline Job control & Job stress & 0.002 \\
\hline Job satisfaction & Job stress & 0.001 \\
\hline Feel about yourself & Job stress & 0.001 \\
\hline Conflict at work & Job stress & 0.001 \\
\hline Social support & Job stress & 0.001 \\
\hline Job future & Job stress & 0.001 \\
\hline Physical environment & Job stress & 0.0001 \\
\hline
\end{tabular}

low safety climate could raise the accident occurrence from 72 to $93 \%$. These results show that two factors of job stress and safety climate play an essential role in the accident occurrence.

Job stress has a significant impact on the occurrence of accidents both directly and indirectly through decreasing the safety climate. Several studies have indicated this path as a direct impact. Barkhordari et al. represented a model that occupational stress can lead to individual failure and carelessness, which can increase unsafe acts or conditions and thereby cause accidents and injuries [34]. The high job stress and imbalance between individual capability and job demand reduce the person's cognitive performance and create cognitive failure. Therefore, individuals cannot decide and act correctly [35]. Chou et al. concluded that perceived occupational stress decreases the cortical activity of the prefrontal cortex [36]. According to Mohammadfam et al., there is a significant direct association between job stress and unsafe acts and accidents. Therefore, the increase of one score in occupational stress enhances the unsafe acts by $1 \%$ [37]. Julia et al. also investigated the relationship between occupational stress and accident occurrence and concluded that there is a significant positive association between them [38]. The results of the present study are compatible with the stated studies. The indirect effect path of the job stress on the accident occurrence was through the effect on the safety climate.

Occupational stress appears to affect the safety climate through two probable significant paths. Job stress 


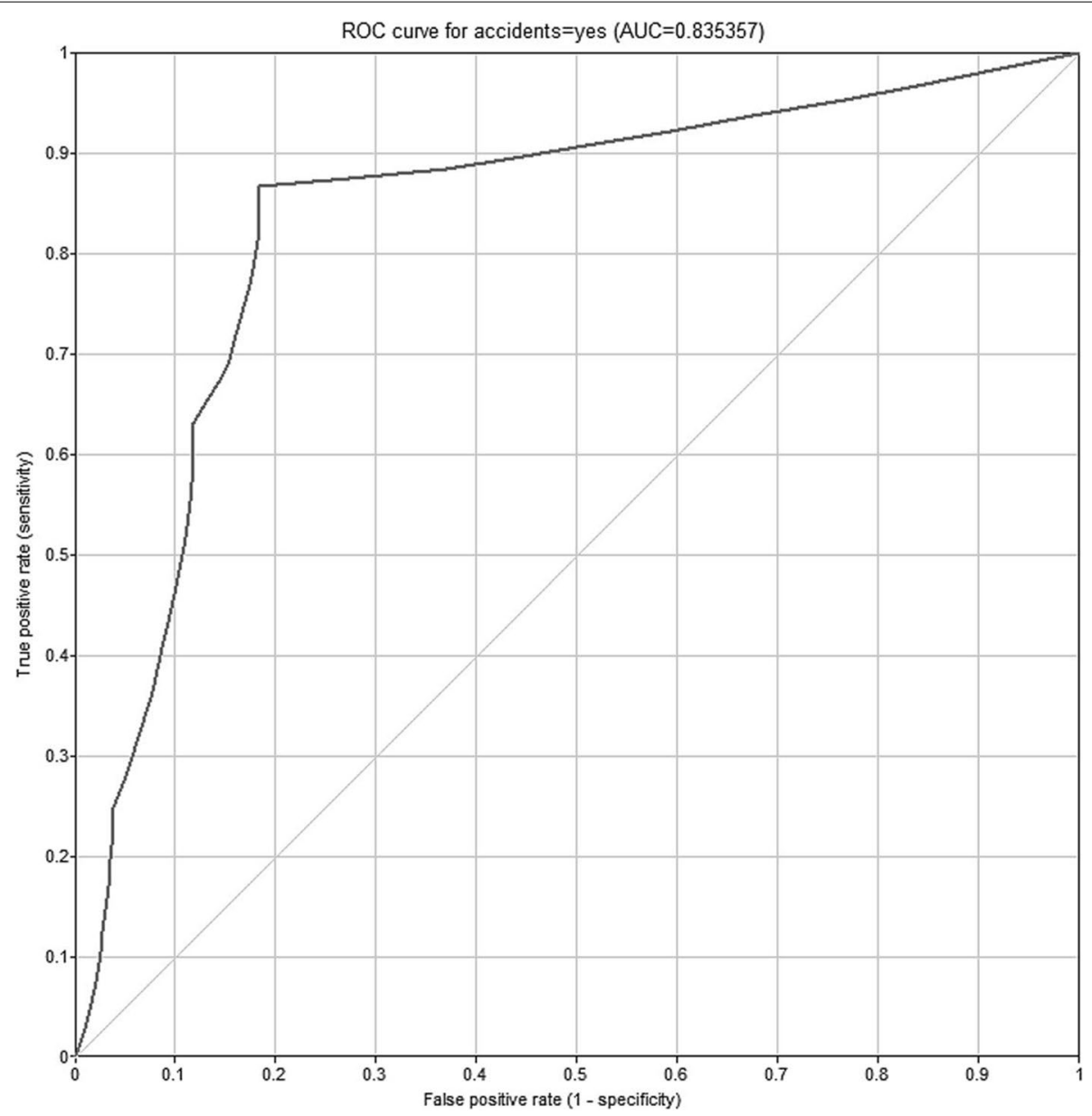

Fig. 7 The ROC curve

can cause physical and psychological consequences. Chronic stress and adverse working conditions cab be resulted in job burnout and cause physical and psychological consequences. The physical effects include hypercholesterolemia, type 2 diabetes, coronary heart disease, hospitalization due to cardiovascular disorder, musculoskeletal pain, changes in pain experiences, prolonged fatigue, headaches, gastrointestinal issues, and respiratory problems. The psychological effects consisted of

Table 5 The confusion matrix related to the classification of the occupational accident status

\begin{tabular}{|c|c|c|c|c|}
\hline & & \multicolumn{2}{|c|}{ predicted } & \\
\hline & & yes & no & \\
\hline \multirow[t]{3}{*}{ actual } & yes & $\mathrm{TP}=988$ & $\mathrm{FN}=151$ & Sensitivity $=87 \%$ \\
\hline & no & $F P=72$ & $\mathrm{TN}=319$ & Specificity $=82 \%$ \\
\hline & & & & Accuracy $=85 \%$ \\
\hline
\end{tabular}

insomnia, depressive symptoms, use of psychotropic and antidepressant medications, hospitalization for mental disorders, and psychological ill-health symptoms. Job dissatisfaction, absenteeism, new disability pension, job demands, job resources, and presenteeism [39]. The results of a study performed by McCaughey et al. showed that workplace injuries and illnesses had negative effects on perceptions of safety climate [40]. On the other hand, job stress may provoke negative feelings in the workplace [41]. These feelings can impress on the job satisfaction of the workers. Stoilkovska et al. concluded that job satisfaction had a significant effect on the perceived safety climate [42].

The results of the present study showed that at the concurrent high job stress and low safety climate situation, the management's safety justice has the most decrease from 53 to $28 \%$ among the safety climate dimensions. On the other hand, the perception of the health problem creates job stress and affects the safety climate. In the current study, however, the relationships between the job 
stress factor and job stress scales, the relations of the job stress factor with general health, work hazard, and other health information showed the highest mean influence values. McCaughey et al. demonstrated that workplace injury and illness have adverse effects on the safety climate perceptions and health care worker outcomes [40]. Hall et al. also concluded that the safety climate modulates the impact of the job demand on depression and further the effect of the depression on the positive organizational behaviors [43].

Also, the results of the present study indicated that at the high job stress condition, most decreases were related to the worker's safety priority and risk non-acceptance, and the worker's safety commitment. Among the associations between the job stress factor and safety climate dimensions, the job stress and worker's safety priority and risk non-acceptance had the highest mean influence value. The results of Griffin et al. study revealed that job stress has a significant positive association with depersonalization and a negative relationship with organizational commitment [44]. Bronkhorst also stated that the job demands, job resources, and safety climate affect the physical and psychological safety behavior and the safety climate has the mediator role in the association between job demands and job resources with the safety behaviors [45]. These results are compatible with the results of the present study.

Limitations of the present study included the lack of data analysis in different parts of the industry and job positions. Also, the effect of non-occupational stress due to family and community environments was not investigated, and the effect of demographic variables on the presented model was not studied. Therefore, it recommends that these limitations be solved in future studies. Besides, the effect of the proposed model on the number and severity of unsafe behaviors and the number and severity of work accidents were not considered, which authors will investigate it in subsequent studies. Lastly, this study applies the self-report instruments as the data source, which may cause some bias in the results.

\section{Conclusions}

In this paper, we utilize the flexible modeling and inference capability BN to perform a study to investigate the effects of job stress and safety climate on the occurrence of an accident. The results of this study showed that the adverse effect of high job stress conditions on accident occurrence is twofold. It can directly increase the accident occurrence probability and in another way, it can indirectly increase the accident occurrence probability by causing the safety climate to go to a lower level. Therefore, to improve the perceived safety climate and decrease the accident occurrence probability, the organizations should put more effort to reduce the job stress on the employee. Some of the strategies for handling the stress in the workplaces included providing a balance between demands and resources, increasing social supports, increasing job control, decreasing role pressures, increasing job satisfaction, increasing job security, and strengthening problem-oriented coping style.

\section{Acknowledgements \\ Researchers need to thank all staff who have participated in this study.}

\section{Authors' contributions}

AHK collected the data and contributed to the manuscript. SY designed the study and wrote the manuscript. MMK and EK were involved in the interpretation of the data, and the coordinator researcher. YH and SK carried out the statistical analyses of the data. All authors read and proved the final manuscript.

\section{Funding}

This study has been supported by Tehran University of Medical Sciences, project number 97-03-61-38355. The funding body has played no role in the design of the study, collection, and analysis of data, interpreting results or in writing the manuscript or in decision to submit the manuscript for publication. The content of this publication is only the responsibility of the authors.

\section{Availability of data and materials}

All data generated and analyzed during this step of the study are included in this published article.

\section{Declarations}

Declaration of Helsinki

The authors confirm that all methods were carried out in accordance with relevant guidelines and regulations.

\section{Ethics approval and consent to participate}

The protocol was reviewed and approved by the Medical Ethics Committee of Tehran University of Medical Sciences (IR.TUMS.VCR.REC.1398.558). All steps of the study were in accordance with the ethical standards. All participants were asked to fill out the consent form developed by the medical ethics committee, and written informed consent was obtained from all of them.

\section{Consent for publication}

Not applicable.

\section{Competing interests}

The authors declare that they have no conflict of interest.

\section{Author details}

${ }^{1}$ Department of Occupational Health Engineering, Faculty of Health, Kashan University of Medical Sciences, Kashan, Iran. ${ }^{2}$ School of Health, Shahrekord University of Medical Sciences, Shahrekord, Iran. ${ }^{3}$ Social Determinants

of Health Research Center, Shahrekord University of Medical Sciences, Shahrekord, Iran. ${ }^{4}$ Occupational Health \& Safety Department, Kashan University of Medical Sciences, Kashan, Iran. ${ }^{5}$ Department of Epidemiology and Biostatistics, School of Public Health, Tehran University of Medical Sciences, Tehran, Iran. ${ }^{6}$ Students'Scientific Research Center, Tehran University of Medical Sciences, Tehran, Iran. ${ }^{7}$ Department of computer science, University of Bradford, Bradford BD7 1DP, UK.

Received: 23 June 2021 Accepted: 24 November 2021

Published online: 07 December 2021

\section{References}

1. Gulhan B, Ilhan M, Civil E. Occupational accidents and affecting factors of metal industry in a factory in Ankara. Türkiye Halk Sağlığı Dergisi. 2012;10(2):76-85. 
2. Hämäläinen P. The effect of globalization on occupational accidents. Saf Sci. 2009;47(6):733-42.

3. Cohen MA, Clark RE, Silverstein B, Sjostrom T, Spielholz P. Work-related deaths in Washington state, 1998-2002. J Saf Res. 2006;37(3):307-19.

4. Khoshakhlagh AH, Yazdanirad S, Laal F, Sarsangi V. The relationship between illnesses and medical drug consumption with the occurrence of traffic accidents among truck and bus drivers in Tehran, Iran. Chin J Traumatol. 2019;22(3):142-7.

5. Blackmore ER, Stansfeld SA, Weller I, Munce S, Zagorski BM, Stewart DE. Major depressive episodes and work stress: results from a national population survey. Am J Public Health. 2007:97(11):2088-93.

6. Lotfi S, Yazdanirad S, Pourabdiyan S, Hassanzadeh A, Lotfi A. Driving behavior among different groups of Iranian drivers based on driver coping styles. Int J Prev Med. 2017;8.

7. Pourabdian S, Lotfi S, Yazdanirad S, Golshiri P, Hassanzadeh A. Evaluation of the effect of fatigue on the coping behavior of international truck drivers. BMC psychology 2020;8(1):1-0

8. Yazdanirad S, Sadeghian M, Naeini MJ, Abbasi M, Mousavi SM. The contribution of hypochondria resulting from Corona virus on the occupational productivity loss through increased job stress and decreased resilience in the central workshop of an oil refinery: a path analysis. Heliyon. 2021;7(4):e06808.

9. Vagg PR, Spielberger CD, Wasala CF. Effects of organizational level and gender on stress in the workplace. Int J Stress Manag. 2002;9(4):243-61.

10. McGrath JE. Social and psychological factors in stress: Illinois Univ at Urbana Dept of Psychology; 1970.

11. Kazronian S, Zakerian S, Saraji J, Hosseini M. Reliability and validity study of the NIOSH generic job stress questionnaire (GJSQ) among firefighters in Tehran city. Health Safety Work. 2013;3(3):25-34.

12. Cassidy T. Stress, cognition and health: psychology press; 1999.

13. M. Goldenhar L, Williams LJ, G. Swanson N. Modelling relationships between job stressors and injury and near-miss outcomes for construction labourers. Work Stress 2003;17(3):218-240.

14. Griffin MA, Neal A. Perceptions of safety at work: a framework for linking safety climate to safety performance, knowledge, and motivation. J Occup Health Psychol. 2000;5(3):347.

15. Zohar D. A group-level model of safety climate: testing the effect of group climate on microaccidents in manufacturing jobs. J Appl Psychol. 2000;85(4):587.

16. Griffin MA, Curcuruto M. Safety climate in organizations. Annual Review of Organizational Psychology and Organizational Behavior. 2016:3:191-212

17. Casey T, Griffin MA, Flatau Harrison H, Neal A. Safety climate and culture: integrating psychological and systems perspectives. J Occup Health Psychol. 2017;22(3):341.

18. Beus JM, Payne SC, Bergman ME, Arthur W Jr. Safety climate and injuries: an examination of theoretical and empirical relationships. J Appl Psychol. 2010;95(4):713.

19. Nahrgang JD, Morgeson FP, Hofmann DA. Safety at work: a meta-analytic investigation of the link between job demands, job resources, burnout, engagement, and safety outcomes. J Appl Psychol. 2011;96(1):71.

20. Kalteh HO, Mortazavi SB, Mohammadi E, Salesi M. The relationship between safety culture and safety climate and safety performance: a systematic review. Int J Occup Saf Ergon. 2021;27(1):206-16.

21. Fogarty GJ, Shaw A. Safety climate and the theory of planned behavior: towards the prediction of unsafe behavior. Accid Anal Prev. 2010;42(5):1455-9.

22. Huang Y-H, Lee J, MCFadden AC, Murphy LA, Robertson MM, Cheung $\mathrm{JH}$, et al. Beyond safety outcomes: an investigation of the impact of safety climate on job satisfaction, employee engagement and turnover using social exchange theory as the theoretical framework. Appl Ergon. 2016:55:248-57.

23. Dollard MF, Tuckey MR, Dormann C. Psychosocial safety climate moderates the job demand-resource interaction in predicting workgroup distress. Accid Anal Prev. 2012;45:694-704.

24. Mohammadfam I, Ghasemi F, Kalatpour O, Moghimbeigi A. Constructing a Bayesian network model for improving safety behavior of employees at workplaces. Appl Ergon. 2017;58:35-47.

25. Aliabadi MM, Pourhasan A, Mohammadfam I. Risk modelling of a hydrogen gasholder using fuzzy Bayesian network (FBN). Int J Hydrog Energy. 2020:45(1):1177-86.
26. García-Herrero S, Mariscal MA, García-Rodríguez J, Ritzel DO. Working conditions, psychological/physical symptoms and occupational accidents. Bayesian network models. Saf Sci. 2012;50(9):1760-74.

27. Ahn G, Hur S, Jung MC. Bayesian network model to diagnose WMSDs with working characteristics. Int J Occup Saf Ergon. 2018.

28. Çetinkaya G, Dicle A. Work stress, perception of job safety, and job satisfaction of rope access technicians and the relationship among them İple Erişim Teknisyenlerinin Iş Stresi, İ̧ Güvenliği Algıları, İ̧ Tatminleri ve Aralarındaki Ilişki Üzerine bir Calıșma. Work Stress. 2017:7(2):125-32.

29. Kines $\mathrm{P}$, Lappalainen J, Mikkelsen $\mathrm{KL}$, Olsen E, Pousette A, Tharaldsen J, et al. Nordic Safety Climate Questionnaire (NOSACQ-50): A new tool for diagnosing occupational safety climate. International Journal of industrial Ergonomics. 2011;41(6):634-46.

30. Yousefi Y, Jahangiri M, Choobineh A, Tabatabaei H, Keshavarzi S, Shams $A$, et al. Validity assessment of the Persian version of the Nordic safety climate questionnaire (NOSACQ-50): a case study in a steel company. Saf Health Work. 2016;7(4):326-30.

31. Sentz K, Ferson S. Combination of evidence in Dempster-Shafer theory: Sandia National Laboratories Albuquerque; 2002.

32. Liu X, Huang G, Huang H, Wang S, Xiao Y, Chen W. Safety climate, safety behavior, and worker injuries in the Chinese manufacturing industry. Saf Sci. 2015;78:173-8.

33. Cao Y, Fang $X$, Ottosson J, Näslund E, Stenberg E. A comparative study of machine learning algorithms in predicting severe complications after bariatric surgery. J Clin Med. 2019;8(5):668.

34. Barkhordari A, Malmir B, Malakoutikhah M. An analysis of individual and social factors affecting occupational accidents. Saf Health Work. 2019;10(2):205-12.

35. Day AJ, Brasher K, Bridger RS. Accident proneness revisited: the role of psychological stress and cognitive failure. Accid Anal Prev. 2012;49:532-5.

36. Chou P-H, Lin W-H, Hung C-A, Chang C-C, Li W-R, Lan T-H, et al. Perceived occupational stress is associated with decreased cortical activity of the prefrontal cortex: a multichannel near-infrared spectroscopy study. Sci Rep. 2016;6:39089.

37. Mohammadfam I, Bahrami A, Fatemi F, Golmohammadi R, Mahjub H. Evaluation of the relationship between job stress and unsafe acts with occupational accidents in a vehicle manufacturing plant. Avicenna Journal of Clinical Medicine. 2008;15(3):60-6.

38. Julià M, Catalina-Romero C, Calvo-Bonacho E, Benavides FG. The impact of job stress due to the lack of organisational support on occupational injury. Occup Environ Med. 2013;70(9):623-9.

39. Salvagioni DA, Melanda FN, Mesas AE, González AD, Gabani FL, Andrade SM. Physical, psychological and occupational consequences of job burnout: a systematic review of prospective studies. PLoS One. 2017;12(10):e0185781.

40. McCaughey D, DelliFraine JL, McGhan G, Bruning NS. The negative effects of workplace injury and illness on workplace safety climate perceptions and health care worker outcomes. Saf Sci. 2013;51 (1):138-47.

41. Kawano Y. Association of job-related Stress Factors with psychological and somatic symptoms among Japanese hospital nurses: effect of departmental environment in acute care hospitals. J Occup Health. 2008:50(1):79-85

42. Stoilkovska BB, Žileska Pančovska V, Mijoski G. Relationship of safety climate perceptions and job satisfaction among employees in the construction industry: the moderating role of age. Int J Occup Saf Ergon. 2015;21(4):440-7.

43. Hall GB, Dollard MF, Winefield AH, Dormann C, Bakker AB. Psychosocial safety climate buffers effects of job demands on depression and positive organizational behaviors. Anxiety, Stress \& Coping. 2013;26(4):355-77.

44. Griffin ML, Hogan NL, Lambert EG, Tucker-Gail KA, Baker DN. Job involvement, job stress, job satisfaction, and organizational commitment and the burnout of correctional staff. Crim Justice Behav. 2010:37(2):239-55.

45. Bronkhorst B. Behaving safely under pressure: the effects of job demands, resources, and safety climate on employee physical and psychosocial safety behavior. J Saf Res. 2015;55:63-72.

\section{Publisher's Note}

Springer Nature remains neutral with regard to jurisdictional claims in published maps and institutional affiliations. 